\title{
On the Double Peak Structure of Thermosyphon Geysering
}

\author{
Agnieszka Kujawska ${ }^{1,2}$, Bartosz Zajaczkowski', M.H. Buschmann² \\ ${ }^{1}$ Wrocław University of Science and Technology, St. Wyspiańskiego 27, 50-370 Wrocław, Poland \\ agnieszka.wlazlak@pwr.edu.pl; bartosz.zajaczkowski@pwr.edu.pl \\ ${ }^{2}$ Institut für Luft- und Kältetechnik gGmbH, Bertolt-Brecht-Allee 20, 01309 Dresden, Germany \\ Matthias.Buschmann@ilkdresden.de
}

\begin{abstract}
With this study we investigate the structure of the geysiring phenomenon occurring in two-phase closed thermosyphons. Geysiring is an instantaneous boiling process caused by an overheating of the working fluid. It is found that under certain thermal conditions pair-geysers and even triple-geysers occur. Based on high frequency pressure recordings the structure of these multi-peaks is revealed. It is argued that the physical reason behind this complex pressure pattern is an insufficient release of thermal energy related to the first bubble.
\end{abstract}

Keywords: Thermosyphon, Geysiring, Pressure.

\section{Introduction}

Two-phase closed thermosyphons (TPCTs) are gravity assisted heat transfer devices utilising phase change heat transfer. A TPCT consists of a sealed and evacuated containment (mainly a cylindrical tube) which is filled with a certain amount of working fluid. Figure 1 (left) shows the three main parts - evaporator, adiabatic section and condenser - of a TPCT. The evaporator is the heated section of the device. The working fluid is boiling here and evaporates. Due to buoyancy the vapor rises through the adiabatic section and reaches finally the condenser. Here cooling takes place so that the vapour condenses on the inner wall of the containment. Due to gravity, the condensate runs along the inner wall of the containment back to the evaporator section and the process continues as long as heat is supplied at the condenser section.

Geyser boiling is a kind of instantaneous operation of thermosyphons which occurs mostly at low pressures, for large filling ratios, or during start-up. The classical view on the geysering-cycle identifies four phases [2]. First, the working fluid is superheated by an external source of heat. During the second phase a vapour bubble emerges and grows rapidly to the size of the containment diameter due to evaporation from the surrounding liquid. Following the growing period the bubble expands and pushes the fluid above it toward the condenser (third phase). The pressure difference between the vapour inside the bubble and inside the TPCT forces the liquid to high speed. Under these circumstances the expelled working fluid may even reach the condenser region. The fourth phase - following the eruption - the expelled working liquid falls back to the working fluid sump remaining in the evaporator and the cycle starts again.

\section{Test rig}

Figure 1 (right) shows a photo of the test rig. Main part of the system is a copper pipe with inner and outer diameters of $d_{i}=20 \mathrm{~mm}$ and $d_{o}=22 \mathrm{~mm}$, respectively. The total length of the device is $l=1.800 \mathrm{~mm}$, including $400 \mathrm{~mm}$ long evaporator and condenser sections consisting of the identical coiled heat exchangers. The thermosyphon is covered with a $20 \mathrm{~mm}$ insulation shell made of Armaflex ${ }^{\circledR}$. The complete test rig is mounted on a rack made of aluminium profiles. After evacuation, the thermosyphon is filled with $85 \mathrm{ml}$ of working fluid deionised water which fills the evaporator to about $68 \%$.

Fluxes of heating and cooling medium - both water - are provided by two identical thermostats (LAUDA Eco RE 1050 $\mathrm{GW}$ ) with a temperature constancy of $\pm 0.02 \mathrm{~K}$. Inlet and outlet temperatures of both cycles are determined directly before and after coiled heat exchangers with Pt100 elements and a maximum uncertainty of $\pm 0.24 \mathrm{~K}$. Temperature in the working fluid sump is measured Internal pressure of the thermosyphon is measured at four different positions along the adiabatic and condenser sections with a measurement frequency of $1 \mathrm{kHz}$ (for details see [2]). Data acquisition is carried out using a message device employing the ProfiSignal software (Delphin Technology AG). 

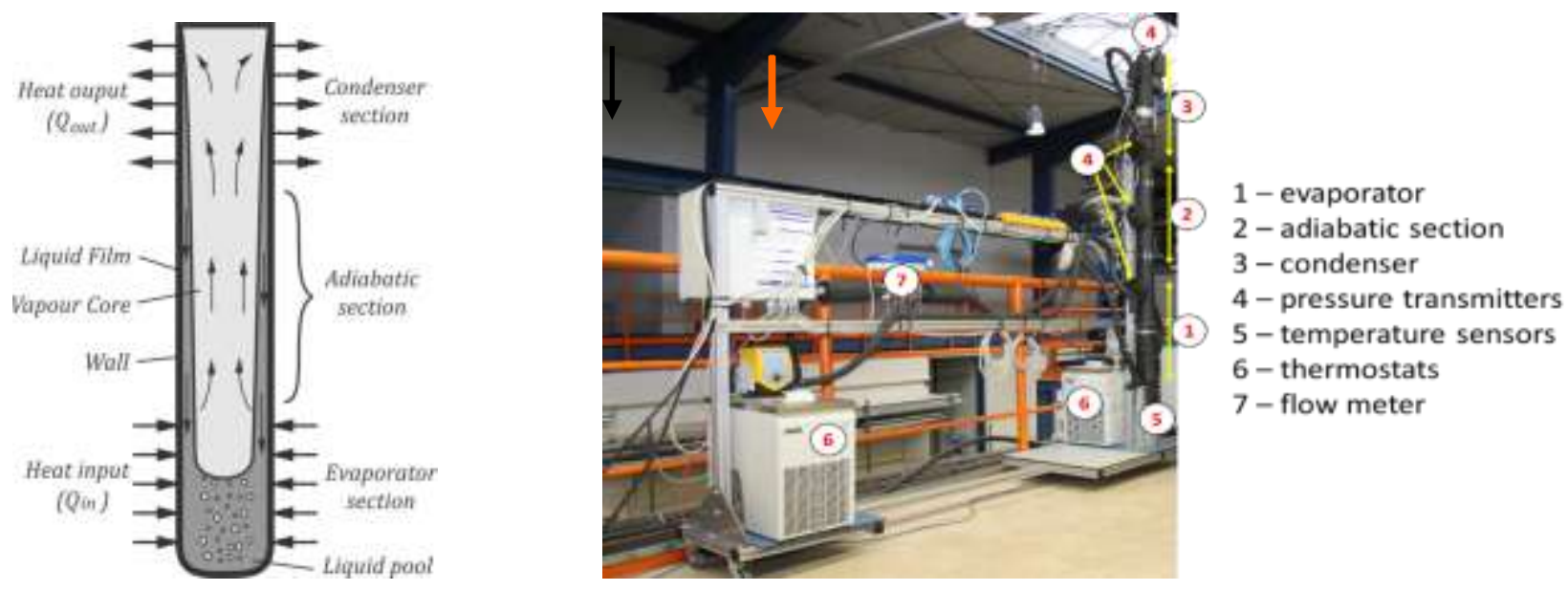

Fig. 1: Thermosyphon working principle (left) adapted from [1] and test rig adapted from [2].

\section{Experimental results}

Experiments are carried out at evaporator inlet temperatures rangig fron $40^{\circ} \mathrm{C}$ to $85^{\circ} \mathrm{C}$ with an increment of $5 \mathrm{~K}$ and condenser inlet temperatures of $15^{\circ} \mathrm{C}$ and $25^{\circ} \mathrm{C}$. Besides the time averaged global parameters of the thermal performance reported in [2] the experiments focuse on the instantaneous pressure distribution inside the TPCT. Figure 2 presents two typical 6 minutes lasting time dependent pressure variations over time. The distributions are normalised by the mean of the pressure during $p_{m}$ the oservation time. Due to the high resolution of $1 \mathrm{kHz}$ detailed information of the geyser cycle are obtained. The most significant part of the cycle is the sharp pressure peak (phase 3) which lasts only for a few milliseconds. It followes a period of instantaneous pressure fluctuations which is caused by the back falling liquid working fluid (phase 4). This period may last for a few seconds. During phase 1 and 2 the pressure is falling monotonically until a minimal value is reached. Short before reaching this minimum, the working fluid is in a metastable state. Even the smallest external disturbances (vibrations, acoustic disturbances etc.) can break this balance and may lead to the outbreak of the next geyser.

Taking a closer look to the pressure distributions of Fig. 2 reveals that some pressure peaks appear in pairs (marked with green circles) or even in triples (dark green ellipse). To investigate this observation on more detail the scaled probability distribution $\langle\omega\rangle P(\tau)$ of the time lapse of two consecutive geysers is analysed (Fig. 3). Normalisation is carried out with the mean time interval $\langle\omega\rangle$ between two geysers and $\tau$ denotes time. Based on the characteristic pressure distribution the time intervals between two consecutive geysers are determined by a computer routine utilising a filter which is set individually for each pressure distribution. The filter consists of a threshold which if exceeded indicates the pressure peak. To avoid a misinterpretation with the following pressure fluctuations following this peak, a waiting time, is defined. Finally the automatically obtained result is verified with the naked eye.

The first thing to notice is that even the two cases shown in Fig. 2 have the same mean inlet temperature of $\left(t_{e i}+t_{c i}\right) / 2=47.5^{\circ}$ the case with the higher evaporator inlet temperature (lower plot) shows more pair-geysers. That leads to the assumption that pair-geysers are mainly generated in the overheated sump and only weakly affected by the condenser. Figure 3 shows one distinct peak of the of the time lapse of two consecutive geysers at about $\tau /\langle\omega\rangle=6 \times$ $10^{3}$ (orange arrow) which is called the first peak. A second peak which is more blurred (purple arrow) is found at about $\tau /\langle\omega\rangle=2.2 \times 10^{3}$. The reason for the weaker characteristic of the second peak is twofold. First of all not each geyser has a second one following as fast as they could form a pair-geyser and second this peak is comparably close to the cutoff by the filter. However, remarkably the scaled probability distribution $\langle\omega\rangle P(\tau)$ shows for a certain range of evaporator and condenser inlet temperature the same characteristic pattern. This finding indicates the geysering cycle takes place in a self-similar manner with respect to its timing. Stochastic effects seem to be are of rather less importance. 

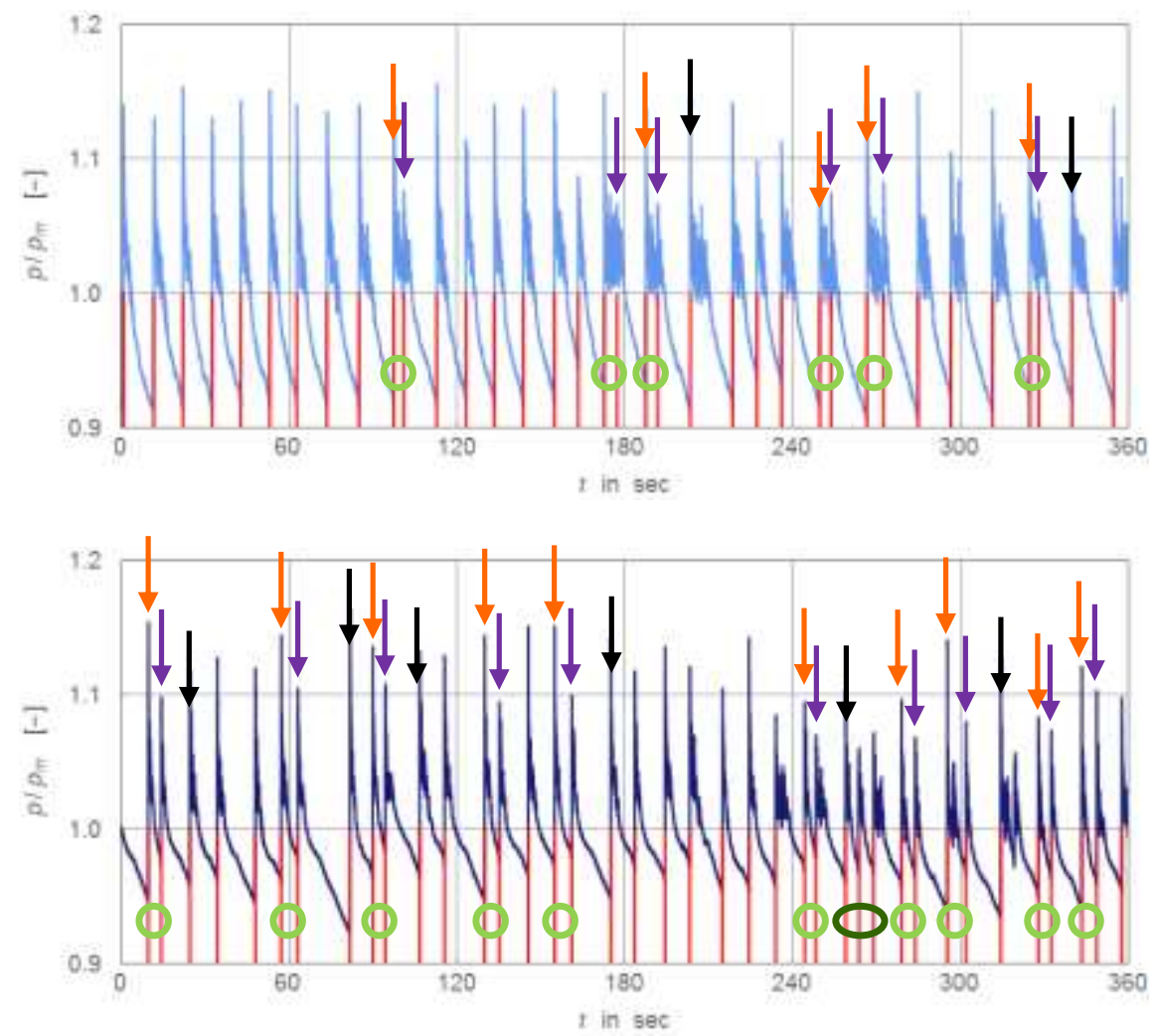

Fig. 2: Time dependent normalised pressure inside TPCT - above evaporator inlet temperature $80^{\circ} \mathrm{C}$ and condenser inlet temperature $15^{\circ}$ and below evaporator inlet temperature $70^{\circ} \mathrm{C}$ and condenser inlet temperature $25^{\circ} \mathrm{C}$. The vertical red lines indicate the pressure peaks identified with the filter. Light green circles mark pair-geysers and the dark green ellipse in the lower plot a triple-geyser.

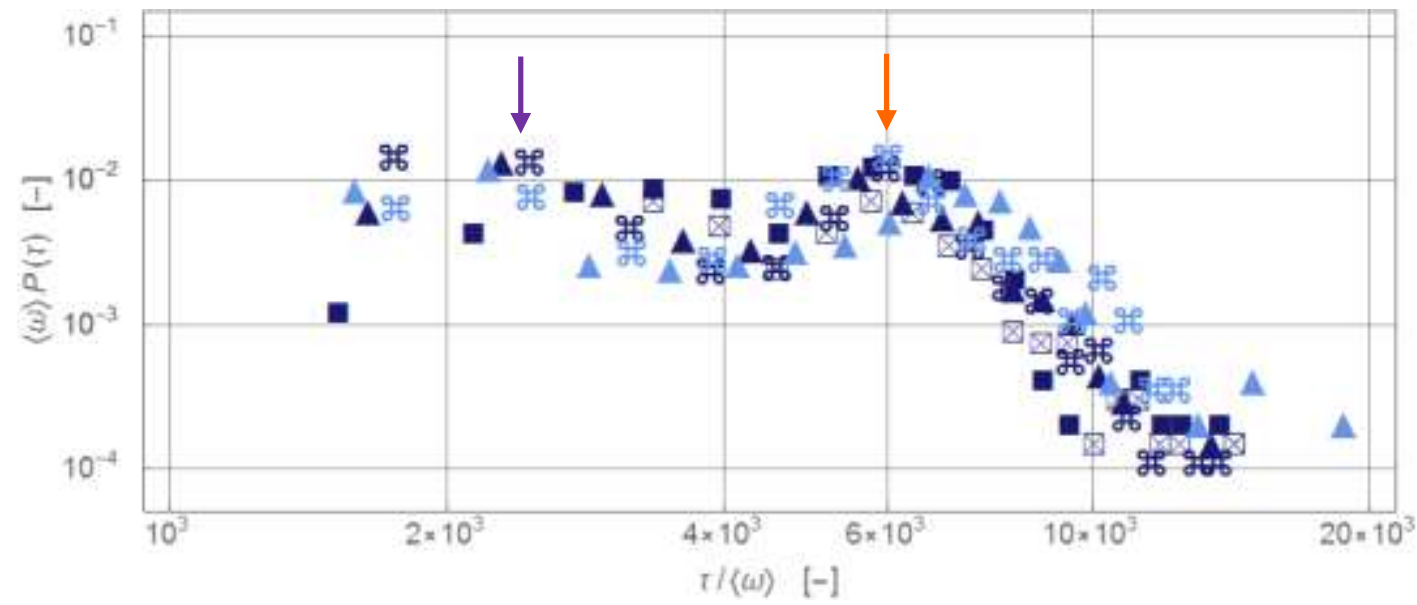

Fig. 3: Scaled probability distribution of the time interval between two consecutive geyser events. Light blue symbols stand for condenser inlet temperature of $15^{\circ} \mathrm{C}$ and evaporator inlet temperatures of $80^{\circ} \mathrm{C}$ and $85^{\circ} \mathrm{C}$ and dark blue symbols stand for condenser inlet temperature of $25^{\circ} \mathrm{C}$ and evaporator inlet temperatures of $70^{\circ} \mathrm{C}, 75^{\circ} \mathrm{C}, 80^{\circ} \mathrm{C}$ and $85^{\circ} \mathrm{C}$.

In Fig. 2 the pressure peaks of the pair-geysers are marked with an orange (fist peak) and a purple arrow (second peak.) In all cases the second peak reaches a lower maximal value than the first one. Moreover, the first pressure peak following the pair-geyser (marked with black arrows) is in the most cases again higher. Based on these findings it is hypothesised that 
the peak intensity is a measure for the thermal energy stored during bubble formation (phases 1 and 2). With the first peak a bubble with a high amount of thermal energy is released. Due to the shorter bubble formation period before the second peak this bubble contains less thermal energy. The second peak is therewith less violent and does not reach the same maximum as the first one. This argumentation is supported by the fact that the pressure minima before the second peak do not reach such low values as the one before the first peak.

The physical reason behind the described scenario might be that after the release of the first bubble (first peak) the working fluid sump is still overheated. Under such circumstance the second bubble would grow faster and reach an instable state earlier than the first bubble.

\section{Conclusion}

Experiments are carried out with a two-phase closed thermosyphon. The TPCT is operated under different thermal conditions by varying the inlet temperatures of evaporator and condenser. The working fluid is water. Main focus of the investigation is the instantaneous pressure pattern related to the geyser-cycle taking place in the device. It is found that for a certain mean temperature range pair-geysers and sometimes even triple-geysers occur. Such a multi-geyser is characterised by more than one significant very short but intense pressure peak. It is argued that multi-geysers are caused by an insufficient release of thermal energy by the first bubble formed in the geysering-cycle.

\section{Acknowledgements}

This work is a contribution to the NanoUptake COST Action (European Cooperation in Science and Technology) CA15119: Overcoming Barriers to Nanofluids Market Uptake. A.K. acknowledges the EU COST for the STMS grant ref. COST-STSM-CA1511935922, 37694 and 39240. M.H.B. acknowledges the support of the Bundesministerium fur

\section{References}

[1] M. H. Buschmann, A. Huminic, S. Mancin, R. R. Riehl, G. Huminic, "State of the art of heat transfer of heat pipes and thermosyphons employing nanofluids as working fluid," J. Nanofluids, vol. 8, pp. 1-14, 2019.

[2] A. Wlazlak, B. Zajaczkowski, M. H. Buschmann, "Geyser boiling in a thermosyphon with nanofluids and surfactant solution," Int. J. Thermal Science, vol. 139, no. 5, 195-216, 2019. 